\title{
Phenotypic variability among patients with hyperornithinaemiahyperammonaemiahomocitru Ilinuria syndrome homozygous for the delF188 mutation in SLC25A15
}

F-G Debray, M Lambert, B Lemieux, J F Soucy, R Drouin, D Fenyves, J Dubé, B Maranda, $R$ Laframboise and $G A$ Mitchell

J. Med. Genet. 2008;45;759-764

doi:10.1136/jmg.2008.059097

Updated information and services can be found at:

http://jmg.bmj.com/cgi/content/full/45/11/759

These include:

References This article cites 24 articles, 2 of which can be accessed free at:

http://jmg.bmj.com/cgi/content/full/45/11/759\#BIBL

Rapid responses You can respond to this article at:

http://jmg.bmj.com/cgi/eletter-submit/45/11/759

Email alerting Receive free email alerts when new articles cite this article - sign up in the box at service the top right corner of the article

Notes

To order reprints of this article go to:

http://journals.bmj.com/cgi/reprintform

To subscribe to Journal of Medical Genetics go to:

http://journals.bmj.com/subscriptions/ 


\title{
Phenotypic variability among patients with hyperornithinaemia-hyperammonaemia- homocitrullinuria syndrome homozygous for the delF188 mutation in SLC25A15
}

\author{
F-G Debray, ${ }^{1}$ M Lambert, ${ }^{1}$ B Lemieux, ${ }^{2}$ J F Soucy, ${ }^{3}$ R Drouin, ${ }^{2}$ D Fenyves, ${ }^{4}$ J Dubé, ${ }^{5}$ \\ B Maranda, ${ }^{6} \mathrm{R}$ Laframboise, ${ }^{6} \mathrm{G}$ A Mitchell ${ }^{1}$
}

${ }^{1}$ Divisions of Medical Genetics, Department of Pediatrics, Centre Hospitalier Universitaire SainteJustine, Université de Montreal, Montreal, Quebec, Canada;

${ }^{2}$ Division of Genetics, Department of Pediatrics, Faculty of Medicine and Health Sciences, University of Sherbrooke, Sherbrooke, Quebec, Canada; ${ }^{3}$ Molecular Genetics Laboratory, McGill University Health Center, Montreal, Quebec, Canada; ${ }^{4}$ Liver Unit, Centre Hospitalier de Université de Montreal, Montreal, Quebec, Canada; ${ }^{5}$ Physiatry, Department of Pediatrics, Centre Hospitalier Universitaire Sainte-Justine, Université de Montreal, Montreal, Quebec, Canada; ${ }^{6}$ Department of Medical Genetics, Centre Hospitalier Universitaire de Quebec and Laval University, Sainte-Foy, Quebec, Canada

Correspondence to: Grant A Mitchell, Division of Medical Genetics, CHU SainteJustine, 3175 Côte SainteCatherine, Montréal, Québec, H3T 1C5, Canada; grant.mitchell@recherche-stejustine.qc.ca

Preliminary results of the study were presented at The Milupa International Workshop on $\mathrm{HHH}$ Syndrome in Rome, Italy, 24 March 2006

Received 18 March 2008 Revised 18 June 2008 Accepted 1 July 2008

\section{ABSTRACT}

Background: Hyperornithinaemia-hyperammonaemiahomocitrullinuria ( $\mathrm{HHH}$ ) syndrome (OMIM 238970) is caused by impaired ornithine transport across the inner mitochondrial membrane due to mutations in SLC25A15 To date, 22 different mutations of the SLC25A15 gene have been described in 49 patients belonging to 31 unrelated families.

Objective: To further delineate the phenotypic spectrum of $\mathrm{HHH}$ syndrome from a description of a genetically homogeneous cohort of patients and identify prognostic factors based on long-term follow-up.

Methods: Sixteen French-Canadian patients were retrospectively and prospectively clinically assessed.

Results: Owing to a founder effect, 15 of the 16 patients were homozygous for the F188del mutation in the SLC25A15 gene. The main clinical features at presentation were liver dysfunction (6/16) and neurological disease (9/16), including chronic neurological symptoms (6/9) and acute encephalopathy (3/9). Hyperammonaemia was not constant and usually mild and uncommon after start of treatment. Long-term follow-up showed that variable intellectual impairment and lower limb spasticity often occur, together or separately, with no obvious relationship to age at diagnosis and compliance with treatment. Conclusion: We report the largest known cohort to date of patients with $\mathrm{HHH}$ syndrome. A similar range of severity occurred in the clinical course and outcome of patients homozygous for delF188 and in the 33 other reported patients compiled from the literature. The poor clinical outcome of some patients with $\mathrm{HHH}$ syndrome despite early treatment and repeatedly normal plasma ammonia levels emphasises the need to better understand the pathophysiology and to reconsider the therapeutic goals for $\mathrm{HHH}$.

Hyperornithinaemia--hyperammonaemia-homocitrullinuria (HHH)syndrome (OMIM 238970) is an autosomal recessive disease caused by impaired ornithine transport at the inner mitochondrial membrane. ${ }^{1}$ Presumably owing to a FrenchCanadian founder effect, $\mathrm{HHH}$ syndrome is relatively common in Quebec, where all patients except one reported to date have been homozygous for the F188del mutation in the SLC25A15 gene. ${ }^{2}$ This provides an opportunity to assess the phenotypic variability among patients with an identical SLC25A15 mutation. Because of its rarity, reports of $\mathrm{HHH}$ syndrome have typically recorded individual case histories or small series, without detailed clinical information about long-term follow-up and outcome. In this study, we sought to describe the phenotypic spectrum of a genetically homogeneous cohort of patients with $\mathrm{HHH}$ syndrome, from initial diagnosis to the present, emphasising longterm course, metabolic control and clinical outcome. We also review and summarise the molecular variants reported to date in SLC25A15.

\section{METHODS}

Informed consent was obtained from patients or their legal guardians. We retrospectively reviewed the medical records of 16 patients with $\mathrm{HHH}$ syndrome diagnosed between 1974 and 2001 in three metabolic centres in Quebec, representing to our knowledge all patients with $\mathrm{HHH}$ syndrome in the province at that time. Clinical, biochemical, neuroradiological and electrophysiological data were noted. All patients were prospectively assessed during 2005 as a part of their routine clinical follow-up. The patients were followed up for a median of 23 years (range 6 to 40).

The early course of patients $1-6$ has been previously reported. ${ }^{3}$ Metabolite levels noted retrospectively included urinary orotic acid, plasma amino acids and plasma ammonia concentrations before and after feeding, which were measured at regular intervals (3-6 months).

Total DNA was purified from peripheral blood leukocytes and the F188del mutation was identified using PCR amplification of an SLC25A15 segment surrounding the deletion, followed by size resolution in a $12 \%$ acrylamide gel. In this assay, the normal sequence produces a 78-bp fragment and the F188del allele, a 75-bp product. SLC25A15 PCR primers (modified form ${ }^{2}$ ) were 5'-GACTCTCAAGCACTTTACTTCG-3' and 5'-AAAAGGACCGGCTCAGTTCATAGC-3'.

\section{Statistical analysis}

Ammonia levels before and after meals were compared using a paired $t$ test. Verbal and nonverbal IO of patients were compared using a Wilcoxon test for paired samples.

\section{RESULTS}

All patients except one were F188del homozygotes. Patient 6 is heterozygous for delF188 and a second, as yet unidentified, allele. One patient (patient 13) died unexpectedly in 2006, aged 23 years. She was 
Table 1 Clinical and biochemical features at presentation of patients with hyperornithinaemia-hyperammonaemia-homocitrullinuria syndrome with the delF188 mutation

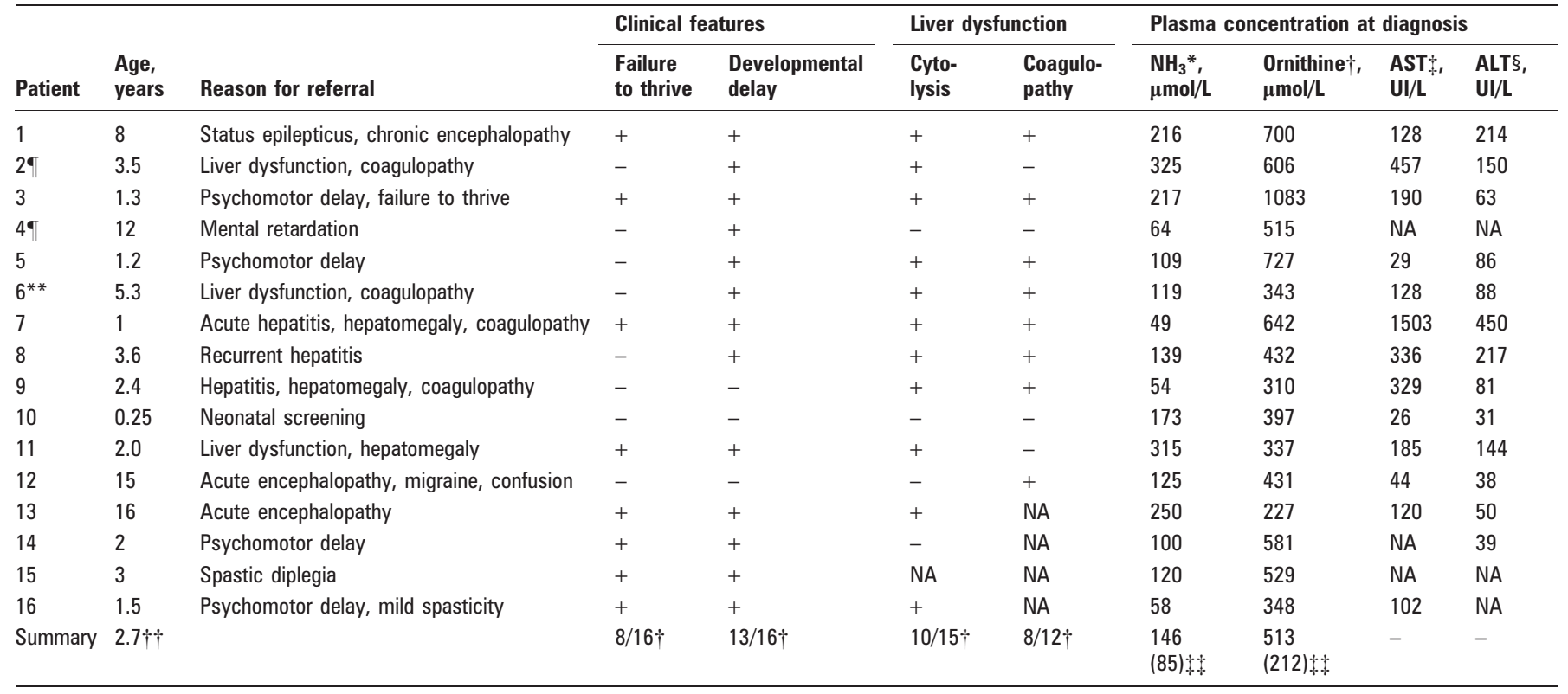

$\mathrm{NA}$, not available; $\mathrm{NH}_{3}$, ammonia.

${ }^{*}$ Higher postprandial plasma concentration before treatment; normal value $<80 \mu \mathrm{mol} / \mathrm{L}$. † Initial plasma concentration before treatment; normal value $<135 \mu \mathrm{mol} / \mathrm{L}$. $\$$ Normal value $<45 \mathrm{UI} / \mathrm{L}$. §Normal value $<45 \mathrm{UI} / \mathrm{L}$. $\left\lceil\right.$ Patients 2 and 4 are siblings. ${ }^{* *}$ Patient 6 has a genetic compound of delF188 and an as yet unknown allele. $\dagger+$ Median. $+\dagger$ Number of patients/ total in group. §§Mean (SD).

found comatose, presenting a hypoxic-ischaemic encephalopathy of unknown aetiology. There had been no prodromal signs, and hyperammonaemia was noticeably absent on admission to hospital, before she was pronounced brain dead.

\section{Initial presentation}

The main clinical features at diagnosis are presented in table 1.

Median age at diagnosis was $\sim 3$ years, ranging from 3 months to 16 years. One presymptomatic patient was detected by the Quebec newborn urinary screening programme, ${ }^{4}$ with a cystinuria-like pattern. Of note, the urinary orotic acid level of this patient was normal in the screening sample at age 3 weeks. For the other patients, the main clinical presentation was either liver disease $(n=6)$ or neurological symptoms $(\mathrm{n}=9)$ including chronic developmental delay or mental retardation $(n=5)$, spastic paraparesis mimicking cerebral palsy $(n=1)$ and acute encephalopathy $(n=3)$. There was no apparent association between the type of presentation and age at diagnosis. Patients with liver presentation were initially investigated for unexplained chronic or recurrent hepatitis-like episodes with mild hepatomegaly and coagulopathy. Five patients presenting with liver signs already had psychomotor delay at diagnosis. Conversely, five patients with neurological presentations also had biological signs of liver dysfunction. Of note, at diagnosis, medical history revealed chronic vomiting and protein intolerance in 14 (88\%) patients. Many patients spontaneously avoided meat and eggs; others were thought to have an allergy to cows' milk.

Hyperammonaemia was found in $12(75 \%)$ patients. It was typically mild and asymptomatic (8/12, 66\%). Only four patients had symptomatic hyperammonaemia. At diagnosis, ornithine concentration exceeded $300 \mu \mathrm{mol} / \mathrm{L}$ in all but one patient. Homocitrullinuria was identified at diagnosis by aminoacid chromatography in all patients.

\section{Treatment and metabolic follow-up}

Patients were treated by protein restriction and sodium benzoate. Protein intake was between 1 and $1.8 \mathrm{~g} / \mathrm{kg} /$ day during childhood and around $40 \mathrm{~g} /$ day in adolescence and later. All patients had normal growth. The three oldest patients never followed any diet and had very poor compliance with treatment. Three patients received arginine supplementation (up to $200 \mathrm{mg} / \mathrm{kg} /$ day), but this was stopped after several months (up to 3 years) because of hyperargininaemia (arginine $>250 \mu \mathrm{mol} / \mathrm{L}$ ). The metabolic follow-up parameters included plasma ammonia and aminoacids measured before and after meals and urinary orotic acid. No patient experienced hyperammonaemic coma under treatment, and post-feeding ammonia concentrations were usually normal. Only three (18\%) patients had recurrent episodes of mild hyperammonaemia (150-250 $\mathrm{mol} / \mathrm{L})$. Surprisingly, we observed a paradoxical decrease of ammonia after feeding in $30 \%$ of the observations (ammonia determination before and after feeding). These changes were plotted against plasma ornithine concentration before feeding (fig 1). The paradoxical decrease in ammonia levels after meals was more common at lower ornithine concentrations. When ornithine before a meal was $>250 \mu \mathrm{mol} / \mathrm{L}$, a significant postprandial ammonia increase was found $(p=0.004)$; whereas for ornithine $<250 \mu \mathrm{mol} / \mathrm{L}$, due to common paradoxical decreases, no increase was noted in mean ammonia levels $(p=0.2)$. As shown (fig 1 ) each patient had fluctuant metabolic parameters over the follow-up course and a paradoxical decrease of ammonia after a meal was observed in many patients, without correlation with motor or cognitive outcome.

\section{Clinical course}

\section{The liver}

Liver involvement was usually limited to asymptomatic biological perturbations (elevated liver transaminases and mild coagulopathy). Usually, liver dysfunction normalised over a few 
Figure 1 Plasma ammonia differences before and after a meal, plotted against plasma ornithine concentration before the meal.

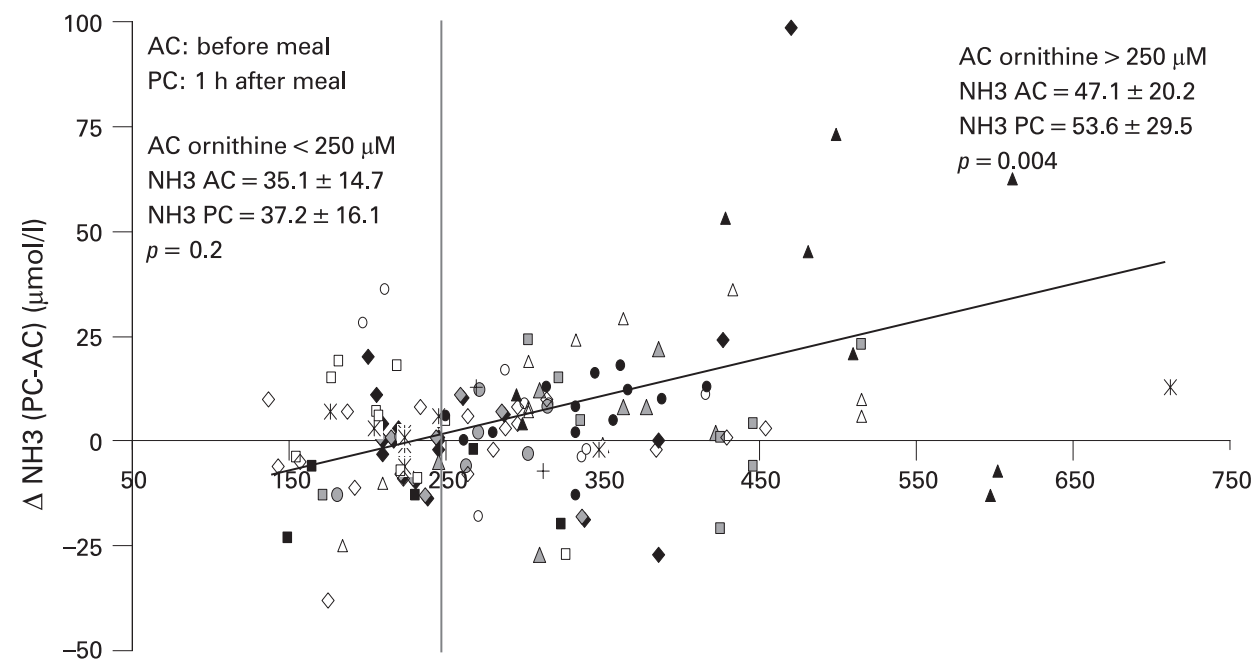

AC ornithine $(\mu \mathrm{mol} / \mathrm{l})$ weeks after starting treatment, beginning with coagulation (over a few days). Liver biopsy in 3 patients showed non specific steatosis or nuclear glycogen deposits. Mitochondrial dysmorphism was identified in one patient as previously reported. ${ }^{5}$

Seven patients (44\%) experienced recurrent episodes of asymptomatic hypertransaminasaemia lasting up to three months. Mild coagulopathy (INR ranging between 1.2 and 3.5) occurred frequently during these episodes. Coagulation factor measurements showed variable patterns of deficiency of factors VII, IX and X. We have a clinical impression that the episodes of hepatic cytolysis were associated with poor compliance with treatment, but this could not be proven statistically with the available data. By contrast, several patients who were essentially not treated because of late diagnosis and/or non-compliance did not experience any hepatitis-like episode. Currently, no patient has any sign of chronic liver disease.

\section{Neurological status}

Psychomotor delay was common in infancy and childhood (15/ 16). The mean age for independent walking was 18 (SD 4) months. There were $5 / 16$ patients with buccolingofacial dyspraxia and $9 / 16$ with poor coordination. Five (31\%) patients had epilepsy, which was easily treated by antiepileptic drug monotherapy. One patient presented with signs of liver dysfunction during valproate therapy, investigation of which lead to the diagnosis of $\mathrm{HHH}$. Seizure type included generalized tonicoclonic (two patients) and myoclonic, partial complex and absence (one patient each). Two other patients had photosensitive electroencephalographic spikes without clinical features. During follow-up, all patients presented signs of pyramidal tract involvement with a marked predominance in the lower limbs: hyper-reflexia (15/16, noted at a median age of 2.5 ears), clonus (11/16, median 4.5 years), tip-toe gait and spasticity (12/14, median 5 years). Four patients received botox injections. Although previous assessment of some of these patients had shown abnormal nerve conduction velocities and somatosensory evoked potentials, suggesting a mild sensorimotor neuropathy, ${ }^{3}$ when examined 13 years later, these patients showed no clinical signs of peripheral neuropathy. Cerebral imaging was available for 13 patients and showed mild cortical atrophy in 4 cases (31\%), severe atrophy in 1 (the oldest) and multifocal T2-weighted hyperintensities in the subcortical white matter in 2 adult patients. No patient had basal ganglia or brainstem lesions. Of note, two adult patients with mental retardation had normal MRI scans. Ophthalmological evaluation of patient 6 had shown retinal depigmentation and chorioretinal thinning at 6 years of age, ${ }^{3}$ but long-term followup did not show any deterioration and at 22 years of age her visual function was normal. Of note, this patient is the only heterozygote for the F188del mutation in this series.

\section{Motor and cognitive outcome}

The current motor, cognitive and functional statuses of patients are presented in table 2 . There are $8 / 16(50 \%)$ patients with obvious spastic paraparesis. All others already have signs of upper motor neuron involvement. Four patients have mental retardation, three have $\mathrm{IO}$ scores in the low average range and four are considered as cognitively unimpaired. However, 13/15 $(86 \%)$ patients experienced learning problems, and none completed regular secondary school. Six patients received methylphenydate for attention deficit-hyperactivity disorder. Of note, verbal IQ was significantly higher $(p<0.001)$ than nonverbal IO.

Only one adult patient (patient 6) is currently completely autonomous and self-sufficient in employment, living and daily activities.

Table 3 summarises the qualitative evaluation of motor and cognitive outcomes and gives information about age at diagnosis and compliance with treatment.

\section{DISCUSSION}

$\mathrm{HHH}$ syndrome is associated with a range of presentations, clinical courses, severity and outcomes. The French-Canadian founder effect provides an opportunity to examine the clinical variability among patients with $\mathrm{HHH}$ syndrome who are homozygous for the delF188 mutation and to compare their clinical courses with those of patients with $\mathrm{HHH}$ syndrome who have other SLC25A15 mutations.

DelF188 results from the in-frame deletion of a TTC triplet within a series of four phenylalanine codons between nucleotides 553 and 564 of the SLC25A15 cDNA. Although SLC25A15 immunoreactive protein is undetectable in fibroblasts of patients with $\mathrm{HHH}$ syndrome homozygous for the delF188 mutation, elegant in vitro studies of recombinant human delF188 protein that was isolated from the inclusion bodies of expressing bacteria, then incorporated into liposomes, 
Table 2 Long-term outcome of patients with hyperornithinaemia-hyperammonaemia-homocitrullinuria syndrome with the F188del mutation

\begin{tabular}{|c|c|c|c|c|c|c|c|c|c|c|}
\hline \multirow[b]{2}{*}{ Patient } & \multirow[b]{2}{*}{$\begin{array}{l}\text { Age, } \\
\text { years }\end{array}$} & \multicolumn{3}{|c|}{ Motor status } & \multicolumn{3}{|c|}{ Cognitive functions } & \multicolumn{3}{|c|}{ Functional independence level* } \\
\hline & & HR & Clonus & $\begin{array}{l}\text { Spastic } \\
\text { gait }\end{array}$ & $\begin{array}{l}\text { Verbal } \\
10\end{array}$ & $\begin{array}{l}\text { Non-verbal } \\
\text { I0 }\end{array}$ & $\begin{array}{l}\text { Global } \\
\text { I0 }\end{array}$ & Job & $\begin{array}{l}\text { Daily } \\
\text { activity }\end{array}$ & Housing \\
\hline $1 \dagger$ & 40 & + & + & NA & NA & NA & 36 & 3 & 3 & 3 \\
\hline 2 & 35 & - & + & - & 64 & 58 & 53 & 2 & 2 & 2 \\
\hline 3 & 25 & + & + & - & 109 & 100 & 105 & 3 & 2 & 2 \\
\hline 4 & 33 & + & - & - & 57 & 54 & 40 & 3 & 3 & 3 \\
\hline $5 \%$ & 21 & + & + & + & 93 & 83 & 87 & 3 & 1 & 3 \\
\hline 6 & 22 & + & - & + & 95 & 80 & 86 & 1 & 1 & 1 \\
\hline $7 \%$ & 14 & + & + & + & 108 & 81 & 92 & & & \\
\hline $8 \%$ & 13 & + & - & - & 110 & 103 & 107 & & & \\
\hline 9 & 9 & + & - & - & NA & NA & 90 & & & \\
\hline 10 & 7 & + & + & - & 98 & 80 & 84 & & & \\
\hline $11 \ddagger$ & 6 & + & + & - & NA & NA & 32 & & & \\
\hline 12 & 29 & + & + & + & 85 & 75 & 79 & 2 & 1 & 1 \\
\hline 13 & 23 & + & + & + & 82 & 78 & 78 & 2 & 2 & 2 \\
\hline 14 & 31 & + & + & + & 76 & 70 & 73 & 2 & 2 & 3 \\
\hline 15 & 17 & + & - & + & 75 & 69 & 71 & & & \\
\hline 16 & 5 & + & + & - & NA & NA & NA & & & \\
\hline
\end{tabular}

HR, hyper-reflexia; NA, not applicable.

*For patients $>18$ years old: 1, autonomous; 2 , supervised; 3 , dependent (or unemployed). $†$ Confined to a wheelchair. $\$$ Received botulinum toxin injections.

demonstrated ornithine transport of $\sim 10 \%$ that of wild type SLC25A15.6 Presumably, the apparently low capacity for ornithine transport combines with the very low level of delF188 protein to cause a marked deficiency of ornithine transport in patients with $\mathrm{HHH}$ syndrome who are homozygous for delF188. In addition to French-Canadians, delF188 has been found in an Italian patient with $\mathrm{HHH}$ with no reported French ancestry. ${ }^{7}$

Reported SLC25A15 mutations in $\mathrm{HHH}$ syndrome patients are presented in table 4, with available clinical data.

Mutations were distributed throughout SLC25A15 and included a variety of mutation types. Most patients were homozygotes for a single mutation. Although lack of clinical information in published reports precludes detailed examination of prognosis and outcome, marked variability in the severity of the clinical presentation was observed and no genotype-

Table 3 Global outcome of patients

\begin{tabular}{llllll}
\hline Pt & $\begin{array}{l}\text { Age, } \\
\text { years }\end{array}$ & Motor & Cognitive & $\begin{array}{l}\text { Age at } \\
\text { diagnosis, } \\
\text { years }\end{array}$ & $\begin{array}{l}\text { Treatment } \\
\text { compliance* }\end{array}$ \\
\hline 1 & 40 & Severe & Severe & 8 & 0 \\
2 & 35 & Mild & Severe & 3.5 & 0 \\
3 & 25 & Mild & Mild & 1.3 & 1 \\
4 & 33 & Mild & Severe & 12 & 0 \\
5 & 21 & Severe & Moderate & 1.2 & $2 \rightarrow 0$ \\
6 & 22 & Severe & Mild & 5.3 & 2 \\
7 & 14 & Severe & Mild & 1 & $2 \rightarrow 1$ \\
8 & 13 & Mild & Mild & 3.6 & 2 \\
9 & 9 & Mild & Mild & 2.4 & 2 \\
10 & 7 & Mild & Mild & 0.25 & 2 \\
11 & 6 & Severe & Severe & 2 & 2 \\
12 & 29 & Mild & Moderate & 15 & 0 \\
13 & 23 & Severe & Severe & 16 & 1 \\
14 & 31 & Severe & Severe & 2 & $1 \rightarrow 0$ \\
15 & 17 & Severe & Moderate & 3 & 1 \\
16 & 5 & Mild & Mild & 1.5 & 2 \\
\hline
\end{tabular}

${ }^{*} 0$, little or none; 1 , moderate; 2 , good compliance; $\rightarrow$, from diagnosis (childhood) to adolescence or adulthood. phenotype correlation was evident, although neurological and liver involvement occurred with all types of mutation. Besides delF188, the only other recurrent allele is R179X, identified in at least four unrelated Japanese patients and 1 Italian patient. ${ }^{10} 15$ Functional characterisation of several mutant SLC25A15 peptides has been assessed in vitro. G27R, IVS5+1G $\rightarrow$ A, c861insG, R179X and R275O showed no detectable transport. G190D demonstrated a residual transport activity of $\sim 35 \%$. ${ }^{6}$ Intriguingly, a genetic compound for G190D and delF188 had a neonatal presentation (table 4), suggesting that patients with residual activity of SLC25A15 may not be protected from early development of clinical signs. To date, functional studies provide no further explanation for the phenotypic variability observed in $\mathrm{HHH}$.

The range of presenting symptoms observed among delF188 homozygotes was similar to those among reported non-delF188 patients with $\mathrm{HHH}$ syndrome. Three main types of initial presentation were observed: (1) liver disease, (2) chronic neurological symptoms and (3) acute encephalopathy. Except for the last one, the presenting symptoms may not direct investigations strongly towards a hereditary metabolic disease, explaining the common misdiagnoses and delays in diagnosis. $\mathrm{HHH}$ should be considered in patients presenting with psychomotor delay and pyramidal syndrome, especially if high-protein food aversion is noted. Hyperornithinaemia is the biochemical hallmark of the disease. Homocitrullinuria is also a constant finding but can sometimes be observed in urine as an exogenous compound in normal formula-fed infants. ${ }^{19}$ Over a third $(37 \%)$ of our patients were diagnosed after investigation for unexplained persistent or recurrent liver dysfunction. Several patients had no hyperammonaemia, suggesting that the diagnosis of $\mathrm{HHH}$ could be overlooked in this context if specific metabolic testing (ie, plasma aminoacid chromatography) is not performed.

Severe but reversible hepatocellular necrosis has recently been reported in $\mathrm{HHH}^{12} 16$ and our series confirms that acute hepatitis-like episodes are common in $\mathrm{HHH}$. Clearly, $\mathrm{HHH}$ should be added to the list of metabolic causes of acute liver disease. ${ }^{20}$ Despite the recurrent hepatitis-like episodes observed 
Table 4 Spectrum of reported SLC25A15 mutations in HHH syndrome

\begin{tabular}{|c|c|c|c|c|c|}
\hline Mutation* & Exon & Predicted protein change & n & Main presenting signs & Reference \\
\hline c. $44 \mathrm{C} \rightarrow \mathrm{A} / 44 \mathrm{C} \rightarrow \mathrm{A}$ & 1 & p.A15E/A15E & 1 & Neonatal hyperammonaemia & 8 \\
\hline c. $80 \mathrm{G} \rightarrow \mathrm{A} / 80 \mathrm{G} \rightarrow \mathrm{A}$ & 2 & p.G27E/G27E & 1 & MR, spastic gait, anterior horn cell degeneration & 9 \\
\hline c. $79 \mathrm{G} \rightarrow \mathrm{A} / 79 \mathrm{G} \rightarrow \mathrm{A}$ & 2 & p.G27R/p.G27R & 1 & Neonatal onset, pyramidal signs, normal cognitively & 10 \\
\hline $\mathrm{c.} .95 \mathrm{C} \rightarrow \mathrm{G} / 95 \mathrm{C}^{-} \rightarrow \mathrm{G}$ & 3 & p.T32R/T32R & $5 \dagger$ & $\begin{array}{l}\text { Mild to no MR, recurrent hepatitis-like episodes, } 1 / 5 \text { patients } \\
\text { died from hyperammonaemic encephalopathy }\end{array}$ & 11 \\
\hline c.96_97insCA/96_97insCA & 3 & p.M330fsX1/M330fsX1 & 1 & $\mathrm{MR}$ & 8 \\
\hline $\mathrm{c} .377 \mathrm{C} \rightarrow \mathrm{G} / 377 \mathrm{C} \rightarrow \mathrm{G}$ & 3 & p.P126R/P126R & 1 & MR, spastic paraparesis & 13 \\
\hline c.446delG/446delG & 3 & p.S149TfsX44/S149TfsX44 & $2 \%$ & $\mathrm{DD}$, seizure, raised liver enzymes & 14 \\
\hline $\mathrm{c} .535 \mathrm{C} \rightarrow \mathrm{T} / 535 \mathrm{C} \rightarrow 7$ & 4 & p.R179X/R179X & $5 \S$ & $\begin{array}{l}\text { MR (except 1), spastic gait, ataxia, episodic } \\
\text { hyperammonaemia, myoclonus (1 patient) }\end{array}$ & 91015 \\
\hline $\mathrm{c} .538 \mathrm{G} \rightarrow \mathrm{A} / 13 \mathrm{q} 14 \mathrm{del}$ & 4 & p.E180K/ne & 1 & NE & 2 \\
\hline c.562_564delTTC/562_564delTTC & 4 & p.F188del/F188del & $>16$ & Heterogeneous presentation (this study) & 216 \\
\hline c.684_685insAAC/684_685insAAC & 5 & p.229insN/229insN & 1 & MR, spastic gait, ataxia, & 9 \\
\hline c. $824 \mathrm{G} \rightarrow \mathrm{A} / 824 \mathrm{G} \rightarrow \mathrm{A}$ & 6 & p.R2750/R2750 & 1 & Mild MR, pyramidal signs & 10 \\
\hline $\mathrm{c} .823 \mathrm{C} \rightarrow \mathrm{T} / 823 \mathrm{C} \rightarrow \mathrm{T}$ & 6 & p.R275X/R275X & 1 & MR, spastic paraparesis, seizures, & 18 \\
\hline c. 861 862insG/861 862insG & 6 & p.E288GfsX2/E288GfsX2 & 1 & Neonatal onset, MR, spastic paraparesis, myoclonus & 10 \\
\hline
\end{tabular}

$\mathrm{DD}$, developmental delay; MR, mental retardation; NE, no expression.

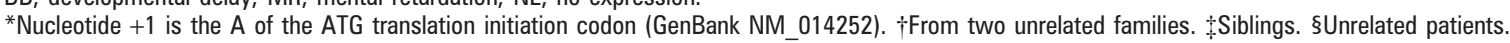

in many patients, none developed chronic liver disease. It shows that the liver is fairly resistant to this chronic metabolic injury and that this metabolic pathway dysfunction in hepatocytes is not sufficiently stressful to induce cumulative liver damages. Why only some patients had liver dysfunction is currently unknown. Acute liver involvement is common in urea-cycle defects. ${ }^{21}$ Because of the genetic homogeneity of our cases, liver sensitivity to the $\mathrm{HHH}$ insult is presumably related to other genetic variants in the urea-cycle pathway or elsewhere in the mitochondrial metabolic network. Of note, the ORNT1 carrier (SLC25A15) is functionally coupled to the citrin (SLC25A13) aspartate-glutamate carrier in the inner mitochondrial membrane of hepatocytes. ${ }^{22}$ One clinical phenotype of citrin deficiency is transitory neonatal hepatitis (neonatal intraheptic cholestasis caused by citrin deficiency, NICCD; OMIM 605814). Pathophysiological links between ORNT1 defeciencies and perturbations of the malate-aspartate and citrate-malate shuttles in hepatitis-like episodes of $\mathrm{HHH}$ remain to be explored. Another candidate modifier could be the SLC25A2 gene, encoding ORNT2, which was shown to rescue ornithine transport when overexpressed in fibroblasts of patients with $\mathrm{HHH}$ syndrome. ${ }^{23}$ Indeed, a SLC25A2 polymorphism with increased activity has been identified and hypothesised to explain phenotypical variability in patients with $\mathrm{HHH}$ syndrome sharing identical mutation. ${ }^{11}$ However, in seven patients harbouring various mutations and variable phenotype, no variation was found in the ORNT2 gene. ${ }^{6}$

Regarding long-term follow-up and outcome, the two main complications commonly observed are cognitive impairment and progressive motor disabilities. Although severe mental retardation is uncommon in patients with $\mathrm{HHH}$ syndrome, most of our adults remain dependent on their parents; only one is fully autonomous. There is no clear association between age at diagnosis and the global outcome (table 4), an observation already reported in another series. ${ }^{7}$ Of note, some adult patients with a late diagnosis and very poor compliance had only mild motor impairment (patients 2, 3, 4 and 12). Conversely, several patients diagnosed in early childhood and who complied with treatment recommendations developed severe lower limb spasticity (table 4). The pyramidal tract involvement of patients with $\mathrm{HHH}$ syndrome is reminiscent of that observed in hyperargininaemia (OMIM 207800), caused by deficiency of the preceding step in the urea cycle. Of note, the two patients (patient 5 and 14) who received arginine for 2 and 4 years, respectively, both have severe spastic paraparesis. Our study provides no support for chronic arginine supplementation in $\mathrm{HHH}$.

Concerning metabolic follow-up, the therapeutic goal is difficult to define. In our experience, urinary orotic acid was the most frequently raised metabolic marker of nitrogen metabolism, usually in the absence of any other sign of metabolic imbalance. Because of this, only major increases of urinary orotate were taken as suggestive of protein overload and led to adjustment of therapy. The standard metabolic goal, avoidance of post-feeding hyperammonaemia, was in practice easily attained by mild protein restriction and sodium benzoate therapy. Despite apparently good metabolic control, the cognitive and motor outcomes of many patients are disappointing. Clearly, hyperammonaemia is not a major factor in the pathophysiological mechanism leading to spastic paraparesis. The development of neurological symptoms despite welldocumented normal or near-normal plasma ammonia levels over the entire course of treatment is a major conclusion of our series and calls for detailed studies of the pathophysiology of $\mathrm{HHH}$ syndrome.

We were intrigued by the frequent and paradoxical decrease of plasma ammonia levels after meals, seen mostly in patients with $\mathrm{HHH}$ syndrome with mild hyperornithinaemia. Low intramitochondrial ornithine levels would limit ureagenesis. Under such circumstances, arginine provided by dietary protein 
might enhance urea synthesis. A similar paradoxical ammonia decrease in plasma ammonia level after meals has been described in delta-1-pyrroline-5-carboxylate synthase deficiency (OMIM 138250), a metabolic disorder with impairment of intramitochondrial ornithine production during fasting. ${ }^{24}$ Interestingly, in our patients, the paradoxical ammonia decrease after a meal was not seen if there were high levels of plasma ornithine. Conversely, ornithine loading failed to prevent amino nitrogeninduced hyperammonaemia in a patient with $\mathrm{HHH}$ syndrome, ${ }^{25}$ which may provide evidence against our hypothesis. Prospective evaluation of ureagenesis before and after standardised protein loads and at different levels of plasma ornithine might clarify the prevalence and reproducibility of this phenomenon. At present we cannot make conclusions about its mechanism. We stress that this phenomenon occurs within the normal range of plasma ammonia concentrations and that it is not predicted to reflect a clinically important metabolic imbalance. Therefore it does not provide an argument in favour of arginine supplementation in patients with $\mathrm{HHH}$ syndrome.

In summary, we report the largest series to date of patients with $\mathrm{HHH}$ syndrome, all but one of whom are delF188 homozygotes. Despite this genetic homogeneity, the clinical presentations and outcomes were as variable as those of other reported patients who have different mutations. The initial symptoms of $\mathrm{HHH}$ are often nonspecific and the diagnosis may be missed if plasma amino acid chromatography is not performed. Hepatic signs may dominate the initial presentation, but resolve rapidly with treatment and long-term hepatic function is normal. There was wide variability in the severity of neurological complications. Overall, the motor and cognitive outcomes of our patients are disappointing. A better understanding of the pathophysiology of $\mathrm{HHH}$ is necessary and the therapeutic goals in this condition should be reconsidered.

Competing interests: None

\section{REFERENCES}

1. Valle D, Simell O. The hyperornithinemias. In: Scriver CR, Beaudet AL, Sly W, Valle S, eds. The metabolic and molecular bases of inherited disease, 8th edn. New York: McGraw-Hill, 2001:1857-95.

2. Camacho JA, Obie C, Biery B, Goodman BK, Hu CA, Almashanu S, Steel G, Casey R, Lambert M, Mitchell GA, Valle D. Hyperornithinaemia-hyperammonaemiahomocitrullinuria syndrome is caused by mutations in a gene encoding a mitochondrial ornithine transporter. Nat Genet 1999:22:151-8.

3. Lemay JF, Lambert M, Mitchell GA, Vanasse M, Valle D, Arbour JF, Dubé J, Flessas J, Laberge M, Lafleur L, Orquin J, Qureshi IA, Dery R. Hyperrammonemiahyperornithinemia-homocitrullinuria syndrome: neurologic, ophthalmologic and neuropsychologic examination of six patients. J Pediatr 1992;121:725-30.

4. Auray-Blais C, Giguere R, Lemieux B. Newborn urine screening programme in the province of Quebec: an update of 30 years' experience. J Inherit Metab Dis 2003;26:393-402.

5. Smith L, Lambert M, Brochu P, Jasmin G, Qureshi IA, Seidman EG. Hyperornithinemia, hyperammonemia, homocitrullinuria $(\mathrm{HHH})$ syndrome: presentation as acute liver disease with coagulopathy. J Pediatr Gastroenterol Nutr 1992:4:431-6.

6. Fiermonte G, Dolce V, David L, Snatorelli FM, Dionisi-Vici C, Palmieri F, Walker JE. The mitochondrial ornithine transporter. J Biol Chem 2003;29:32778-83.
7. Salvi S, Santorelli FM, Bertini E, Boldrini R, Meli C, Donati A, Burlina AB, Rizzo C, Di Capua M, Fariello G, Dionisi-Vici C. Clinical and molecular findings in hyperornithinemia-hyperammonemia-homocitrullinuria syndrome. Neurology 2001;57:911-14.

8. Shih VE, Ficicioglu C. Genotype and phenotype findings in the hyperornithinemiahyperammonemia-homocitrullinuria $(\mathrm{HHH})$ syndrome. J Inherit Metab Dis 2000;23(Suppl):72.

9. Tsujino S, Kanazawa N, Ohashi T, Eto Y, Saito T, Kira J, Yamada T. Three novel mutations (G27E, insAAC, R179X) in the ORNT1 gene of Japanese patients with hyperornithinemia, hyperammonemia and homocitrullinuria syndrome. Ann Neurol 2000;47:625-31.

10. Salvi S, Dionisi-Vici C, Bertini E, Verardo M, Santorelli FM. Seven novel mutations in the ORNT1 gene (SLC25A15) in patients with hyperornithinemai, hyperammonemia and homocitrullinuria syndrome. Hum Mutat 2001;18:460.

11. Camacho JA, Mardach R, Rioseco-Camacho N, Ruiz-Pesini E, Derbeneva 0 andrade D, Zaldivar F, Qu Y, Cederbaum SD. Clinical and functional characterization of a human ORNT1 mutation (T32R) in the hyperornithinemia-hyperammonemia-homocitrullinuria (HHH) syndrome. Pediatr Res 2006;60:423-9.

12. Fecarotta S, Parenti G, Vajro P, Zuppaldi A, Della Casa R, Carbone MT, Correra A, Torre G, Riva S, Dionisi-Vici C, Santorelli FM andria G. HHH syndrome (hyperornithinaemia, hyperammonaemia, homocitrullinuria), with fulminant hepatitislike presentation. J Inherit Metab Dis 2006;29:186-9.

13. Miyamoto T, Kanazawa N, Hayakawa C, Tsujino S. A novel mutation, P126R, in a Japanese patient with HHH syndrome. Pediatr Neurol 2002;26:65-7.

14. Korman SH, Kanazawa N, Abu-Libdeh B, Gutman A, Tsujino S. Hyperornithinemia, hyperammonemia and homocitrullinuria syndrome with evidence of mitochondrial dysfunction due to a novel SLC25A15 (ORNT1) gene mutation in a Palestinian family. J Neurol Sci 2004;218:53-8.

15. Miyamoto T, Kanazawa N, Kato S, Kawakami M, Inoue $Y$, Kuhara T, Inoue T, Takeshita K, Tsujino S. Diagnosis of Japanese patients with HHH syndrome by molecular genetic analysis: a common mutation, R179X. J Hum Genet 2001;46:2602.

16. Mhanni AA, Chan A, Collison M, Seifert B, Lehotay DC, Sokoro A, Huynh HQ, Greenberg CR. Hyperornithinemia-hyperammonemia-homocitrullinuria syndrome $(\mathrm{HHH})$ presenting with acute fulminant hepatic failure. J Pediatr Gastroenterol Nutr 2008;46:312-15.

17. Al-Hassnan ZN, Rashed MS, Al Dirbashi OY, Patay Z, Rahbeeni Z, Abu-Amero KK. Hyperornithinemia-hyperammonemia-homocitrullinuria syndrome with stroke-like imaging presentation: clinical, biochemical and molecular analysis. J Neurol Sci 2008;264:187-94.

18. Torisu H, Kira R, Kanazawa N, Takemoto M, Sanefuji M, Sakai Y, Tsujino S, Hara T. A novel R275X mutation of the SLC25A15 gene in a Japanese patient with the $\mathrm{HHH}$ syndrome. Brain Dev 2006;28:332-5.

19. Metwalli AA, Lammers WL, Van Boekel MA. Formation of homocitrulline during heating of milk. J Dairy Res 1998;65:579-89.

20. Clayton PT. Diagnosis of inherited disorders of liver metabolism. J Inherit Metab Dis 2003;26:135-46.

21. Nassogne MC, Heron B, Touati G, Rabier D, Saudubray JM. Urea cycle defects: management and outcome. J Inherit Metab Dis 2005;28:407-14.

22. Saheki T, Kobayashi K, lijima M, Horiuchi M, Begum L, Jalil MA, Li, MX, Lu YB, Ushikai M, Tabata A, Moriyama M, Hsiao KJ, Yang Y. Adult-onset type II citrullinemia and idiopathic neonatal hepatitis caused by citrin deficiency: involvement of the aspartate glutamate carrier for urea synthesis and maintenance of the urea cycle. Mol Genet Metab 2004;81:S20-6.

23. Camacho JA, Rioseco-Camacho N andrade D, Porter J, Kong J. Cloning and characterization of human ORNT2: a second mitochondrial ornithine transporter that can rescue a defective ORNT1 in patients with the hyperornithinemiahyperammonemia-homocitrullinuria syndrome, a urea cycle disorder. Mol Genet Metab 2003;79:257-71.

24. Baumgartner MR, Hu CA, Almashanu S, Steel G, Obie C, Aral B, Rabier D, Kamoun $P$, Saudubray JM, Valle D. Hyperammonemia with reduced ornithine, citrulline, arginine and proline: a new inborn error caused by a mutation in the gene encoding delta-1-pyrroline-5-carboxylate synthase. Hum Mol Genet 2000;9:2853-8.

25. Simell 0, Mackenzie S, Clow CL, Scriver cr. ornithine loading did not prevent induced hyperammonemia in a patient with hyperornithinemia-hyperammonemiahomocitrullinuria syndrome. Pediatr Res 1985;19:1283-7. 